\title{
Sociabilidades, edição, educação: o Annuário Brasileiro de Literatura como projeto educativo (1937-1944)*
}

\section{Sociabilities, edition, education: The Brazilian Literature Yearbook as an education project (1937-1944)}

\author{
Luciano Mendes de Faria Filho**
}

\begin{abstract}
RESUMO
Este artigo se propõe a analisar o periódico Annuário Brasileiro de Literatura (ABL), publicado entre 1937 e 1944, como lugar de sociabilidade e órgão de educação da intelectualidade brasileira. O ABL se constituiu, no período, num dos mais importantes e influentes periódicos brasileiros. No texto, buscamos mostrar que ele fazia parte de um investimento de construção da unidade nacional, do intercâmbio entre agentes intelectuais diversos (escritores, editores, jornalistas etc.) e de um esforço para colocar o Brasil no concerto das nações civilizadas. O periódico propunha o congraçamento da intelectualidade a favor da unidade nacional, ao mesmo tempo que reafirmava que tal unidade não poderia prescindir da riqueza de nossa diversidade histórica, cultural e geográfica. Finalmente, apontamos que o ABL buscava educar e mobilizar os intelectuais sem descurar, no entanto, de um olhar sobre a educação escolar vista como uma condição, ou como um
\end{abstract}

DOI: $10.1590 / 0104-4060.53220$

* Este artigo se vincula ao Projeto de Pesquisa Moderno, modernidade, modernização: a educação nos projetos de Brasil-1820/1970, em desenvolvimento, coordenado pela prof ${ }^{\mathrm{a}}$. Raylane Navarro, da Universidade Tiradentes e da Fundação de Amparo à Pesquisa do Estado de Minas Gerais - FAPEMIG, com o apoio do Conselho Nacional de Desenvolvimento Científico e Tecnológico, da Coordenação de Aperfeiçoamento de Pessoal de Nível Superior e da Fundação de Apoio à Pesquisa e à Inovação Tecnológica do Estado de Sergipe, por meio do Programa de Estímulo a Mobilidade e ao Aumento da Cooperação Acadêmica da Pós-Graduação em Instituições de Ensino Superior de Sergipe - PROMOB. Esse projeto reúne mais de duas dezenas de pesquisadores em diversos níveis de formação - graduação, mestrado, doutorado, pós-doutorado -, os quais buscam compreender os modos como a educação aparece nos projetos de Brasil propostos e debatidos pela intelectualidade brasileira nos dois últimos séculos.

** Universidade Federal de Minas Gerais. Faculdade de Educação. Belo Horizonte, Minas Gerais, Brasil. Av. Antônio Carlos, nº 6627. Pampulha. CEP: 31270-901. E-mail: lucianom@ufmg.br 
obstáculo, à ampliação do mercado editorial e, portanto, do esclarecimento da população brasileira.

Palavras-chave: Intelectuais. Estado Novo. Periódicos brasileiros.

\begin{abstract}
This article aims to analyze the periodic Annuário Brasileiro de Literatura (Brazilian Literature Yearbook, ABL), published between 1937 and 1944, as a place of sociability and as an education organ of Brazilian intellectuality. ABL became in the period, one of the most important and influent Brazilian periodic publications. In the text, we intend to demonstrate that it was part of an investment for the construction of national unity, of an exchange among several intellectual agents (writers, editors, journalists, etc.) and an effort to put Brazil in a group of civilized nations. The periodic proposed the conciliation of intellectuality in favor of national unity, while at the same time reaffirming that such unity could not do away with the richness of our historical, cultural and geographic diversity. Finally, we pointed that the ABL aimed to educate and mobilize the intellectuals; however, they did not stop themselves from looking at school education as as a condition, or an obstacle to the amplification of the editorial market - and, therefore, of the clarification of the Brazilian population.
\end{abstract}

Keywords: Intellectuals. New State. Brazilian periodics.

\title{
Introdução
}

A década de 1930, segundo farta bibliografia (SORÁ, 2010; MICELI, 2001; DE LUCA, 2011; FARIA FILHO, 2017), foi um momento profícuo na criação e consolidação de meios de expressão intelectuais, notadamente de editoras e periódicos. Segundo Miceli (2001), foi um momento de expansão do mercado editorial e de fortalecimento da profissionalização dos diversos sujeitos a ele relacionados, principalmente editores e escritores.

Uma das marcas daqueles densos e tensos anos de 1930 foi, segundo De Luca (2011), uma expansão bastante acentuada do número de periódicos dedicados aos mais variados temas, notadamente, à cultura, à política e à educação. Por meio deles, a intelectualidade brasileira se congregava e disputava as interpretações do Brasil, bem como os postos-chave no mercado editorial e político que se organizava. Tais periódicos se constituíam em lugares e redes 
de sociabilidade e permitiam, aos seus praticantes, "imaginar comunidades de intelectuais" (SORÁ, 2010, p. 144) em atuação no país.

É nesse contexto que, em 1937, logo no alvorecer do Estado Novo, a comunidade intelectual brasileira via nascer o Annuário Brasileiro de Literatura - $\mathrm{ABL}$, um dos mais importantes e influentes periódicos brasileiros da passagem das décadas de 1930 a 1940. Os ABLs foram publicados entre 1937 e 1944 e faziam parte de um investimento de construção da unidade nacional, do intercâmbio entre agentes intelectuais diversos (escritores, editores, jornalistas etc.) e de um esforço por colocar o Brasil no concerto das nações civilizadas.

O que se sentia e se pensava naquele momento era que o país, no que diz respeito à vida intelectual e, particularmente, editorial, estava vivendo um momento de transição. A respeito da vida editorial e intelectual brasileira, o editor, em carta ao leitor, no primeiro número assevera:

Vimos, em Porto Alegre, uma typografia fundada em 1883, numa velha casa colonial de duas portas e uma vitrina transformar-se numa das maiores casas editorais (se não a maior) do Brasil. Assistimos, em São Paulo, a transformação de uma pequena fábrica de livros na grande editora Nacional. E aqui no Rio de Janeiro, constatamos quase um milagre: um jovem cheio de coragem e boa vontade, tomar a peito a divulgação dos intelectuais de mérito e, em quatro anos, construir um monumento admirável, todo de mármore e granito, e nele inscrever com letras de outros nomes que ficarão para sempre nos fatos da nossa história literária - José Lins do Rego, Lúcio Cardoso, Graciliano Ramos, Jorge Amado, Almir de Andrade, Sérgio Buarque de Hollanda. (NEVES, 1937, p. 6).

Nossa intenção neste artigo é analisar, de forma mais detida e aprofundada, as formas como a educação - as instituições educativas, as ações do Estado e as iniciativas editoriais - comparece nas páginas dos ABLs. Mas não apenas isso, pois também nos interessa entender os próprios ABLs como sendo um repertório portador de uma dimensão educativa, não escolar, que se realizaria por meio da criação de um ambiente denso de sociabilidades intelectuais.

Os repertórios culturais não se prendem exclusivamente a uma filosofia específica, tampouco ganham forma como resultado de propaganda política. Eles emergem em processos históricos específicos e estão imbricados ao campo cultural de uma época. Para Ann Swidler (1989), eles funcionam como "caixa de ferramentas", às quais recorrem os agentes sociais, selecionando recursos conforme suas necessidades de compreender certas situações e definir linhas de 
ação. Trata-se, portanto, de um complexo de hábitos, habilidades e estilos, de visões de mundo, formas de pensar e formas de agir empregados pelas pessoas em diferentes configurações para definir e construir linhas de ação.(SWIDLER, 1989, p. 273).

Partindo das formulações de Charles Tilly e Ann Swindler, Ângela Alonso adverte que os repertórios são compostos por padrões analíticos, por noções, argumentos, conceitos, teorias, esquemas explicativos, formas estilísticas, figuras de linguagem e metáforas, não importando a consistência teórica entre seus elementos. "Seu arranjo é histórico e prático". (ALONSO, 2002, p. 39).

Mobilizada por nós, a noção de sociabilidades indica não apenas uma intenção de congraçamento e reunião de intelectuais, mas também um engajamento interessado na realização de um determinado projeto político cultural e, por isso, educativo. Tomamos, de empréstimo, as elaborações de Ângela Castro Gomes para quem as abordagens das sociabilidades procuram

captar a ambiência sócio-político-cultural da cidade, para então mapear a dinâmica de articulação de seus vários grupos intelectuais reunidos em lugares de sociabilidade por eles legitimados, para o debate e a propagação de ideias, indissociáveis de formas de intervenção na sociedade. (GOMES, 1999, p. 10).

Ainda, segundo a autora, o estudioso das sociabilidades "concentra sua atenção na lógica de constituição de seus grupos, postulando interdependência entre formação de redes organizacionais e os tipos de sensibilidades aí desenvolvidos." (GOMES, 1999, p. 10).

Esta abordagem seria segura e profícua para o historiador, por permitir uma aproximação das obras dos intelectuais, através do privilegiamento das condições sociais em que foram produzidas, enquanto constitutivas de um certo campo político-cultural. Sendo mais precisa (...) [trata-se] do reconhecimento da existência de um campo intelectual com vinculações amplas, porém com uma autonomia relativa que precisa ser reconhecida e conhecida. Isto poderia ser alcançado com uma investigação que acompanhasse as trajetórias de indivíduos e grupos; que caracterizasse seus esforços de reunião e de demarcação de identidades em determinados momentos; e que associasse tais eventos às características estéticas e políticas de seus projetos. (GOMES, 1999, p. 11). 
De modo igual, e por isso mesmo, no programa de pesquisa dessa historiadora, ganha relevo o estudo dos lugares de sociabilidade, entendidos estes como periódicos, correspondências, casas editoras, cafés, livrarias e associações culturais; ou seja, a diversidade dos lugares "onde os intelectuais se organizam, mais ou menos formalmente, para construir e divulgar propostas". (GOMES, 1999, p. 11).

No artigo pretendemos, pois, "aplicar" aos ABLs um questionário que busca indagar sobre a forma como a educação escolar é ali referida - em textos dos articulistas, nos livros citados, resenhados ou, ainda, nas referências à legislação e às ações do Estado na área. Além disso, como já nos referimos, nosso questionário buscará abarcar as variadas formas de como os próprios ABLs funcionam: um repertório utilizado pelos intelectuais que incorporam um ethos educativo com a clara intencionalidade de agir sobre a realidade brasileira, mais especificamente sobre a comunidade intelectual e sobre o público leitor brasileiro.

Apesar de ser amplamente referido e/ou estudado em outras áreas, o ABLé pouco conhecido (ou referido) pela área de História da Educação. Por isso, este artigo buscará, em primeiro lugar, estabelecer o clima intelectual daqueles densos e tensos anos de 1930 e 1940. Em seguida, chamará a atenção para a discussão sobre o mercado editorial brasileiro e para a intensa ação de produção de periódicos existentes no período e à qual a ação dos Irmãos Pongetti veio se somar.

Em terceiro lugar, pretende-se fazer uma descrição dos ABLs em sua materialidade, incluindo formas de organização do conteúdo e da diagramação. Por último, nós nos dedicaremos a uma análise das formas de como a dimensão educativa, escolar ou não, é abraçada e explicitada pelos sujeitos que fazem os ABLs, incluindo-se aqui uma abordagem das dimensões educativas das sociabilidades intelectuais.

\section{O Brasil na imaginação intelectual}

Publicados inicialmente pelos Irmãos Pongetti - editores em franca ascensão no mercado editorial e crescente prestígio entre os pares -, os ABLs tinham um propósito muito amplo, como ressalta Gustavo Sorá:

Os ABL se organizavam sob a lógica do resumo anual, com a intenção nativa de perguntar: o que foi feito em matéria artística, intelectual e editorial? Como é a produção cultural nos Estados e em outros países 
civilizados? Quais setores de atividades criativa se desenvolvem com mais ênfase, ou quais são mais representativos? Como comunicar e conseguir a unidade nacional em um imenso país que mal se conhece? Qual o estado da evolução de nossa cultura? Que posição nos cabe, como resultado, no concerto das nações civilizadas? O que deve ser feito? (SORÁ, 2010, p. 343).

Tais propósitos se revelavam a partir da capa dos anuários e se realizavam num conjunto muito expressivo de textos que buscavam construir uma imagem multifacetada do país para os próprios intelectuais. Mas, ao mesmo tempo, era realizado o esforço de mostrar que as grandes diferenças intra e inter-regionais não foram empecilhos para se imaginar um país único e intelectualmente vigoroso.

A capa do primeiro anuário é reveladora dos propósitos da publicação: reunir e divulgar num mesmo veículo as letras, as artes e a ciência. Tal propósito é reforçado no editorial de J. L. Costa Neves, que o enfatiza ao nomear alguns dos representantes dessas três áreas que comparecem às páginas do anuário: a crítica literária com Agripino Grieco, Eloy Pontes e Carlos Chiacchio; a poesia com Onestaldo de Pennafort, Murilo Araújo, Menotti Del Picchia, Martins Fontes e Osório Dutra; a "erudição" com Gilberto Freire, Arthur Ramos, Alcides Bezerra, Eduardo Frieiro e Sílvio Júlio. Isso tudo sem falar dos vários membros da Academia Brasileira de Letras que aí comparecem. (ABL, 1937, p. 5).

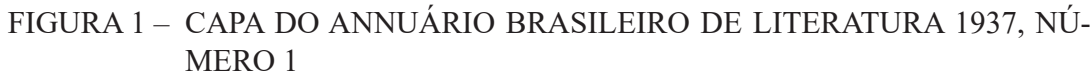
MERO 1

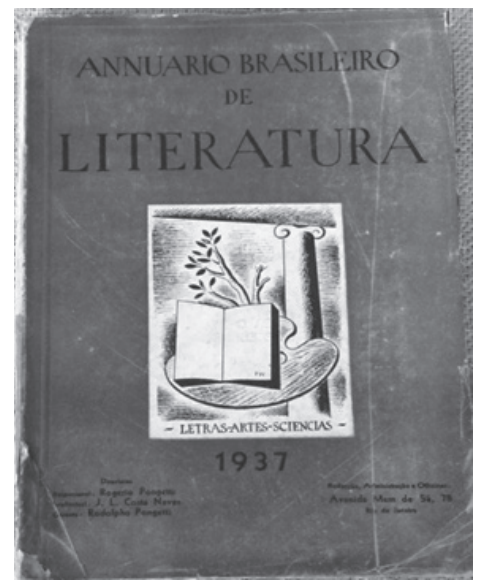

FONTE: Biblioteca Nacional. 
FIGURA2 -CAPA DO ANUÁRIO BRASILEIRO DE LITERATURA 1939, NÚMERO 3

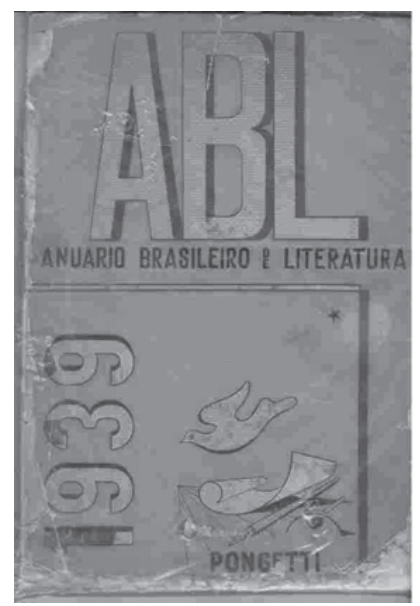

FONTE: Biblioteca Nacional.

A utilização da capa como um importante protocolo de leitura e um reforço aos propósitos do periódico, que se repete em todos os números publicados. No número 3, de 1939, no momento que recrudescem os preparativos para a guerra, a capa traz uma clara mensagem de paz, representada pela pomba branca e pela mimetização de um avião de guerra por uma "mensagem" de paz, que sobrevoa acompanhada pelo instrumento de trabalho do intelectual: a pena.

Da mesma forma, a capa do $\mathrm{ABL}^{\circ}{ }^{\circ}$, de 1940, busca jogar luz no esforço realizado pelo próprio período na revelação do Brasil e de sua singular posição no mundo. E o faz por meio da estratégia de jogar um foco de luz no mapa do Brasil no globo.

Assim, conforme detalha Sorá (2010, p. 348), os editores dos ABLs estabeleciam diversas formas de dar a ver e "de se ver o Brasil". Seja por meio da exposição de temas (educação, língua, leitores, livros), seja por meio do relato de viagens (no Brasil e em outros países), seja, ainda, por meio da "simples" reunião de uma multidão de autores, publicando seus textos ou fazendo referência a seus livros, em suas páginas, os anuários buscavam contribuir para mostrar um país diverso, mas unido. 
FIGURA 3 - CAPA ANUÁRIO BRASILEIRO DE LITERATURA 1940, NÚMERO 4

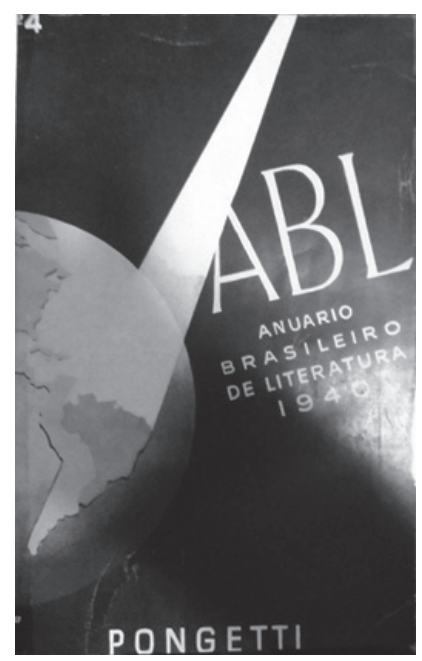

FONTE: Biblioteca Nacional.

Se a união se fazia por meio da ação dos intelectuais, havia também o esforço, sobretudo a partir do segundo e do terceiro números, em reafirmar a importância da ação de Vargas para a manutenção da unidade e para o desenvolvimento nacional. Para isso, imagens de Vargas e textos a ele relacionados passam a ser constantes no periódico.

Portanto, não é por acaso que os editores publicam na $\mathrm{ABL} \mathrm{n}^{\circ} 4$, de 1940, o texto "O Estado Novo e o Intelectual", que se refere ao trabalho do jornalista e colaborador Barbosa Lima Sobrinho, o qual lembra sua nomeação para a direção do Instituto do Açúcar e do Álcool, ocorrida dois anos antes. Nisso aproveitam a ocasião para enaltecer a boa relação do governo Vargas com os intelectuais. Segundo eles,

O Estado Novo, pela própria essência de renovação, teve, desde o início, a preocupação de entregar os postos de comando aos maiores valores mentais do País [...].

O "Anuário Brasileiro de Literatura", expondo aos leitores a obra de Barbosa Lima Sobrinho, nos mais variados departamentos da inteligência, e destacando seu excepcional trabalho de jornalista, presta homenagem não somente a ele, mas a todos que mourejam na imprensa brasileira. (ABL, 1940, p. 328). 
Ao explicitar a sua adesão à política de cooptação desenvolvida amplamente pelo governo Vargas em relação aos intelectuais, sobretudo a partir do ministério comandado por Capanema, os responsáveis pelo ABL buscam se estabelecer como mediadores entre o Estado e os Intelectuais e vice-versa. Nessa posição, podem, eventualmente, abrigar intelectuais contrários ao governo varguista, mas podem, sobretudo, granjear certas benesses políticas e econômicas distribuídas pelos órgãos de Estado.

\section{A face educativa dos ABLs}

Além das dimensões educativas que se realizavam pelas informações que colocavam em circulação, pela revelação do próprio país à intelectualidade brasileira e, ainda, pela função de organização do campo intelectual brasileiros e da indústria editorial nacional, para qual chamava a atenção Gustavo Sorá (2010), não era alheio a seus proprietários e editores que eles desempenhariam, também, uma clara função educativa. Essa dimensão é explicitada já no editorial do número inicial, publicado em 1937.

Vimos também o Brasil - este com maior razão, si se atentar na extensão do seu território e nas grandes distâncias existentes entre os centros mais populosos e cultos - precisava de uma publicação dessa natureza. E se bem o pensaram, melhor levaram a cabo. Trata-se de empreendimento de alta significação, cujos frutos benéficos todos hão de reconhecer: 1ivreiros, leitores, autores e o próprio Governo, que terá no "ANNUÁRIO BRASILEIRO DE LITERATURA" um auxiliar eficiente para sua obra de educação popular. (NEVES, 1937, p. 6).

É evidente que a educação popular, aqui, não é fundamentalmente a que se realiza na escola. É a de tradição iluminista, da qual fala R. Darnton (1996), que encontra nos editores entusiasmados propagadores e realizadores, inclusive porque se trata da razão e subsistência de seus negócios.

Da leitura do conjunto dos textos publicados, depreende-se claramente que a função educativa do anuário se dirige, por um lado, para os próprios intelectuais e para os profissionais do livro e, por outro, para o governo e para a população brasileira. 
Os ABLs, de forma reiterada, dirige-se aos intelectuais como sendo estes seus leitores de primeira linha e seus interlocutores mais diretos. Mas, quem seriam os intelectuais a que se referem continuamente os editores? Eles são mencionados de modo genérico em um sem número de textos, mas, de forma não muito usual, são nomeados mais claramente num pequeno texto denominado "Propaganda e Cultura" publicado no ABL n 3, de 1939.

A Companhia Nestlé, como homenagem às classes intelectuais do Brasil, representada pelos educadores, sociólogos, médicos, higienistas, escritores e estudiosos em geral, resolveu lançar algumas publicações de natureza verdadeiramente cultural, abordando os mais variados assuntos, e valorizadas com a assinatura dos mais prestigiados nomes da inteligência brasileira. (ABL, 1939, p. 282).

Percebe-se, pois, que as classes intelectuais são abrangentes e variadas ao se referir a todos que desenvolvem algum tipo de trabalho intelectual, geralmente com formação superior. Se são esses os intelectuais que precisam ser congregados e educados para que possam ter consciência coletiva de seu papel na educação do próprio governo e dos brasileiros, não menos importante é o reforço à autoimagem positiva, empreendedora e esclarecedora, dos empresários do livro e dos desafios que cercam os profissionais que atuam no setor. Assim é constante o investimento na revelação dos números da indústria editorial brasileira e as renovações pelas quais vem passando, o que é feito com muito entusiasmo desde o primeiro volume, assim como é reiterada a dificuldade de se obter dados mais completos e confiáveis para o estabelecimento de uma estatística do livro no Brasil.

Talvez este primeiro número, elaborado com alguma dificuldade - coisa aliás fácil de se compreender, não corresponde inteiramente ao escopo em mira. Nem todos os editores patrícios tiveram a boa vontade ou o claro discernimento de prestar os esclarecimentos necessários a completar e deixar sem falhas um órgão informativo como este. Talvez que com o aparecimento do primeiro número vejam a razão de ser dos insistentes pedidos que lhes fizemos no devido tempo. Por exemplo, a estatística do livro de literatura não nos foi possível levantá-la, por falta absoluta de elementos para o fazer". (ABL, 1937, p. 7). 
Portanto, apesar de esclarecidos e esclarecedores, os editores precisavam compreender que não lhes bastava trazer os livros à lume, era preciso atuar sobre os leitores como um grupo coeso e colaborativo. Mas, também, os editores não perdiam de vista que o Brasil precisava ser educado.

Território imenso, escassez de comunicações, falta ou deficiência de instrução entre o povo, despreocupação por parte dos poderes públicos, e várias outras cousas de menor importância, concorrem, entretanto, para manter quase ignorado, a não ser nos âmbitos em que vivem e agem, todos esses índices de nosso desenvolvimento intelectual. (ABL, 1937, p. 7).

"O problema mais árduo e complexo de nosso tempo é a formação do homem”. Assim iniciava Pedro Calmon, membro da Academia Brasileira de Letras, o texto "Palavras à juventude" que apareceu no ABL no 3 em 1939. Nele, o acadêmico, fazendo uso de repertório amplamente disseminado à época, articulava a pedagogia à política: "a suprema solução da pedagogia e da política, exatamente por ser a da inteligência e do sentimento, é a compreensão", e afirmava que "educação é reajustamento" e que "instrução é dominação". (CALMON, 1939, p. 89).

Ajustar a juventude ao seu tempo, ajudando-a a compreender os grandes desafios de sua época, é o papel da educação. Armar as novas gerações para dominar o mundo, e até a morte se necessário, é o papel supremo da instrução! Mas não basta isso, é preciso o concurso de outro elemento, o espiritual: "Dominareis. Dentro na vossa época, porque ora ela vos educastes. Robusto pelo que sabeis; fortes pelo sentimento que tendes da vossa missão individual; e guiados por um espiritualismo o que é, na confusão contemporânea, o maior bem da cultura." (CALMON, 1939, p. 90).

Desse modo, comungando ou não com esse pensamento, boa parte dos diagnósticos que se faz sobre o Brasil aponta que algumas de nossas maiores dificuldades, inclusive para a ação dos intelectuais em seu meio - a "dominação" de que falava Calmon - radica-se na falta da escola e no analfabetismo da população.

Mas, como pedagogia e política não estão desarticuladas, cobra-se e, às vezes, celebra-se a presença forte e centralizadora do Estado para o estabelecimento de uma pedagogia cívico-cultural. Tal pedagogia deveria ser mobilizadora da escola e também deveria alcançar grupos e setores sociais específicos, além dos estratos geracionais das crianças e dos jovens. 
Além de estarem sujeitas a uma pedagogia escolar, seria fundamental que as crianças e jovens tivessem acesso, por exemplo, a bons livros. Não por acaso, a temática da literatura para crianças ou a literatura infantil é tema de um número significativo de textos. Se, na maior parte deles, elas, as crianças, são focadas como leitoras, em artigo publicado no $\mathrm{ABL} \mathrm{n}^{\circ}$ 3, de 1939, Danilo Bastos defende "que as crianças escrevam as suas histórias". Segundo ele,

Esse trabalho, de revelar aos poucos à alma das crianças as verdadeiras imagens da realidade que as rodeia, não será nunca bem feito se empreendido por um adulto. Este nunca se fará compreender. Antes, porque não sabe insinuar as suas intenções, decaindo num pedagogismo soporífico, e depois porque será dificílimo atrair a atenção da criança utilizando as visões mesmas da sua espontaneidade de ação e reação.

Daí a necessidade de uma literatura feita pelas crianças, das histórias contadas pelas suas próprias personagens. [...].

A verdadeira literatura infantil é aquela que reflete as preocupações, as ideias, as incompreensões da alma infantil. (BASTOS, 1939, p. 153).

Impunha-se, pois, nas páginas dos ABLs, o repertório político-pedagógico que há muito vinha mobilizando os educadores brasileiros em formas diversificadas de apropriação dos preceitos escolanovistas. Àquela altura, a compreensão e a valorização da ação das crianças eram, como sabemos, uma das facetas centrais do repertório político, pedagógico e intelectual mobilizado por um conjunto expressivo de sujeitos, das mais variadas profissões, que buscavam, há algumas décadas, reformar o Brasil por meio da reforma educacional. (VIDAL, 2001).

Dentre os vários aspectos da cultura brasileira e dos debates intelectuais dos anos de 1930, merece destaque a presença da população negra nas páginas do anuário. De forma mais contundente, a temática é discutida no texto "A cultura Negra”, de Jacy Rêgo Barros, publicado no ABL n 3, de 1939. Sintomaticamente o artigo começa afirmando que

O simples título dessa crônica, - Cultura negra - em um período não muito distante do de nossos dias, seria motivo de escândalo a afirmação tácita da ignorância do articulista. Seria, então, portador de cultura para os meios lusos aquele negro vindo para essas plagas em porões escuros de Navios Negreiros? (BARROS, 1939, p. 251). 
Após se perguntar, retoricamente, onde estariam, então, as "universidades africanas, ou melhor seus filósofos, seus artistas etc.”(BARROS, 1939, p. 251), o articulista afirma que, contrariando a visão comum, mas compartilhada por muitos de nossos pensadores de outrora, "a condição servil poderia modificar a conduta social do negro mas o homem interior lá estava com suas crenças e os seus temores orientados pelas quigilas e não pelo diabo que o Cristianismo por sua vez havia também sacado de crença outros" (BARROS, 1939, p. 251).

Assim, de uma penada só, Jacy Barros afirma a existência de uma cultura negra - se entendida à luz das contemporâneas noções que este termo inclui -, e acusa o cristianismo de se apropriar de culturas outras para erigir as suas crenças. Mas, de uma forma muito peculiar, o autor defende a existência de uma "mestiçagem cultural", de fundamental importância para se entender o Brasil.

As gerações legitimamente africanas vão desaparecendo, mas o mulatismo que as sucede não afirmaria a mestiçagem apenas numa questão de pigmento, mas num plano mais importante que o daquele, que é precisamente o da cultura.

$[\ldots]$

Dois passados se encontram na encruzilhada do destino, o europeu e o africano, e seria ingênuo o imaginar-se que não se mesclassem para concerto mais eficiente de uma caminhada comum, e assim se deu, realmente, revelando-nos esse consórcio magnífico o folclore brasileiro, onde, religiosamente, por exemplo, ora é Jesus quem está presente ora é olorum, ora é o Diabo, ora é exu, ora é a cuíca, ora a guitarra e assim por diante, para não nos referirmos aos sublastro que lá está em toda a sedimentação ameríndia. (BARROS, 1939, p . 251-252).

Essa mesma perspectiva de valorização da contribuição da população negra ao Brasil e de combate aos preconceitos contra ela, aparece no "Preconceito de Raça”, de Damião Mendonça, colocado no alto da página 230, do $\mathrm{ABL} \mathrm{n}^{0}$ 5, de 1941, aparentemente para preencher espaço na diagramação.

Que importa a cor da minha pele, escura, que eu tenha o lábio espesso, e meu nariz nunca me traia a descendência obscura de um lar de vãs riquezas, infeliz?!

Que importa eu não pertença a casta pura, e os pósteros não usassem flor de lis, 
se da cor, dede o Império, a vil tortura

foi p'ra sempre banida em meu país?!

À gloria de vive, apenas vale

um conjunto de ações nobilitantes,

que, de fazê-las, sinta-se ventura.

Pois a muitos, que à pele ostentam alvura,

E só cometem coisas infamantes,

duvido que em negruras alguém se iguale.

Essa perspectiva positiva, quanto à presença e à importância da população negra na constituição da cultura brasileira, é apenas uma das muitas formas de percebermos como os ABLs dialogavam com as grandes questões de seu tempo e, sem dúvida, de que seus editores tomavam partido. Conforme nos lembra Isaia (2012), ainda que se referindo aos estudos sobre a umbanda,

as palavras do intelectual umbandista Jacy Rego Barros, são altamente indiciárias das elaborações simbólicas dos discursos de parte da "inteligentsia” brasileira e do Estado Novo, no afã de representar um Brasil mestiço, cujo povo ostentava uma harmonia racial que se prolongava nas demais relações sociais. Durante o Estado Novo, Jacy Rego Barros ministrou um curso sobre umbanda, posteriormente publicado, obviamente com autorização governamental, onde fez apologia da figura da "mãe preta", como exemplo de um passado "harmônico" e "não violento". (ISAIA, 2012, p. 17-18).

Assim, dialogando com as principais questões de seu tempo e se esforçando por congregar os editores e intelectuais no sentido de produzir a unidade brasileira em meio à diversidade política, cultural e histórica do país, os editores e demais agentes que atuaram na produção dos ABLs se mostraram sensíveis e argutos quanto às necessidades do emergente campo intelectual brasileiro. Contudo, é evidente que eles também não deixaram de atuar na produção dessas mesmas necessidades. As facetas complementares desses intelectuais mediadores (GOMES; HANSEN, 2016) buscavam, a um só tempo, participar da longa tradição, própria aos produtores de livros, e refundar o Brasil a partir da ação política que representava pôr em circulação novas interpretações sobre o país. 
Nesse sentido, não é por acaso que há uma clara aproximação do ABL com as políticas do Estado Novo sem, no entanto, com elas se mimetizar totalmente. Nisso os editores da revista, eles também editores de livros, aproximavam-se de boa parte da intelectualidade brasileira que acreditava que aquele era um momento novo, talvez único, em que suas colaborações eram demandadas e financiadas pelo Estado brasileiro com o intuito de passar o país a limpo, inclusive por meio da reinterpretação de seu passado.

Funcionando como uma espécie de mediador intelectual institucional ou coletivo, o ABL se constituiu, por sua vez, como uma forma de intervenção política de um grupo de intelectuais coordenados pelos editores do periódico. Esse grupo, com raízes em praticamente todas as dimensões ou áreas da vida intelectual, cultural e política brasileiras, buscava estabelecer uma política educativa que, apesar de incluir a escola, era muito mais ampla. O ABL se configurou, pois, como uma experiência relevante de política cultural como política educativa que buscou capturar a tudo e a todos para seu raio de interesse e, num certo sentido, de ação.

Mas, sem deixar de ser político-cultural, o ABL foi, também, uma experiência de autorreflexão e tomada de posição dos agentes do mercado editorial brasileiro na busca de novos leitores; ou seja, de novos consumidores do produto cultural que suas empresas produziam: os livros. Assim, enquanto buscavam produzir e/ou reforçar redes de sociabilidades que possibilitassem a educação dos próprios editores e dos escritores nacionais, os responsáveis pelo periódico não deixaram de vislumbrar uma nova sociabilidade, baseada no livro, para boa parte da população brasileira.

\section{REFERÊNCIAS}

ALONSO, A. Ideias em movimento: a geração de 1870 na crise do Brasil Império. São Paulo: Paz e Terra, 2002. p. 39.

BARROS, J. R. A cultura negra, $A B L$, Rio de Janeiro, n. 3, p. 251-252, 1939.

BASTOS, D. As crianças escrevem suas histórias. ABL, Rio de Janeiro, n. 3, p. 153154, 1939.

CALMON, P. Palavras à juventude. $A B L$, Rio de Janeiro, n. 3, p. 89-90, 1939.

DARNTON, R. O iluminismo como negócio. São Paulo: Cia das Letras, 1996. 
DE LUCA, T. R. Leituras, projetos e (re)vistas do Brasil (1916-1944). São Paulo: UNESP, 2011.

FARIA FILHO, L. M. de. Edições e Sociabilidades Intelectuais. Belo Horizonte/Ed. Autêntica/Ed. UFMG, 2017.

GOMES, A. M. de C. G. Essa gente do Rio: modernismo e nacionalismo. Rio de Janeiro: FGV, 1999.

GOMES, A. M. de C. G; HANSEN, P. S. Intelectuais mediadores. Rio de Janeiro: Civilização Brasileira, 2016.

ISAIA, A. C. Umbanda, intelectuais e nacionalismo no Brasil. Fênix, v. 9, n. 3, p. 1-22, 2012.

MENDONÇA, D. Preconceito de Raça. ABL, Rio de Janeiro, n. 5, p. 230, 1941.

MICELI, S. Inteligência à Brasileira. São Paulo: Cia das Letras, 2001.

NEVES, J. L. C. Leitor amigo. ABL, Rio de Janeiro, n. 1, p. 5-7, 1937.

SORÁ, G. Brasilianas: José Olympio e a gênese do mercado editorial brasileiro. São Paulo: Edusp, 2010.

SWIDLER, A. Culture in action: symbols and strategies. American Sociological Review, n. 51, p. $273,1989$.

VIDAL, D. G. O exercício disciplinado do olhar: livros, leituras e práticas de formação docente no Instituto de Educação do Distrito Federal (1932-1937). Bragança Paulista: Editora da Universidade São Francisco, 2001.

\section{Documentos consultados}

ANNUÁRIO BRASILEIRO DE LITERATURA, Rio de Janeiro, Pongetti Editores, n. $1,1937,316 \mathrm{p}$.

ANNUÁRIO BRASILEIRO DE LITERATURA, Rio de Janeiro, Pongetti Editores, n. $3,1939,544 \mathrm{p}$.

ANNUÁRIO BRASILEIRO DE LITERATURA, Rio de Janeiro, Pongetti Editores, n. 4, 1940, 416p.

Texto recebido em 12 de junho de 2017.

Texto aprovado em 19 de junho de 2017. 